\title{
EXPERIMENTAÇÃO EM QUADRINHOS CONTEMPORÂNEOS: A PROPOSTA HÍbRIDA DE PEDRO FRANZ
}

\author{
CONTEMPORARY COMIC \\ EXPERIMENTATION: THE HYBRID \\ PROPOSAl OF PEDRO FrANz
}

\section{EXPERIMENTACIÓN EN HISTORIETAS CONTEMPORÁNEAS: LA PROPUESTA HÍBRIDA DE PEDRO FRANZ}


RESUMO: O presente artigo tem como objetivo apresentar a história em quadrinhos Promessas de amor a desconhecidos enquanto espero o fim do mundo de Pedro Franz, dividida em três volumes e publicada entre 2010 e 2012, demonstrando sua relaçáo híbrida com os quadrinhos, as artes visuais e a literatura, pensando no modo como a obra passa por um processo de desterritorialização e se mescla a elementos de diferentes linguagens artísticas para criar sua singularidade, seu próprio território em constante tensão.

ABSTRACT: This article aims to present the comic book Promessas de amor a desconhecidos enquanto espero o fim do mundo of Pedro Franz, divided into three volumes and published between 2010 and 2012, demonstrating its hybrid relationship with comics, visual arts and literature thinking about how the work goes through a process of deterritorialization and merges with elements of different artistic languages to create its singularity, its own territory in constant tension.

RESUMEN: El presente artículo tiene como objetivo presentar la historieta Promessas de amor a desconhecidos enquanto espero o fim do mundo de Pedro Franz, dividida en tres volúmenes y publicada entre 2010 y 2012. Se evidencia su relación híbrida con las historietas, las artes visuales y la literatura, además de pensar en cómo la obra pasa por un proceso de desterritorialización y se mezcla a elementos de diferentes lenguajes artísticos para crear su singularidad, su propio territorio en constante tensión.

PALAVRAS-CHAVE: Literatura e Artes visuais; Quadrinhos Contemporâneos; Experimentação; Território; Pedro Franz.

KEYWORDS: Literature and Visual Arts; Contemporary Comics; Experimentation; Territory; Pedro Franz.

PALABRAS CLAVE: Literatura y Artes Visuales; Historietas Contemporáneas; Experimentación; Territorio; Pedro Franz.

Promessas de amor a desconhecidos enquanto espero o fim do mundo de Pedro Franz é uma obra que mescla literatura, artes visuais e histórias em quadrinhos. Por meio de experimentaçóes, ela transita entre diferentes campos artísticos, criando um território em mutação que violenta o presente e reflete os conflitos na HQ. A estrutura não canônica desse objeto artístico exige uma crítica alinhada ao posicionamento subversivo da obra, que não se enquadra em um modelo tradicional ou em um campo artístico exclusivo, 
estando em constante estado de desterritorialização e reterritorialização (DELEUZE e GUATARRI, 1996), isto é, em constante movimento que violenta e afeta as relaçóes da obra com outros pontos de referência.

O autor Pedro Franz nasceu em Florianópolis em 1983, graduou-se em design gráfico pela Universidade Federal de Santa Catarina em 2008 com a pesquisa A quarta dimensão do trabalho de Breccia, nela analisou a carreira e a produção em quadrinhos do uruguaio Alberto Breccia que publicava semanalmente em jornais argentinos e possuiu uma proposta de vanguarda durante toda sua carreira. Em 2010, Pedro Franz iniciou sua carreira como quadrinista com a obra Promessas de Amor a Desconhecidos Enquanto Espero o Fim do Mundo², divida em três volumes: Limbo (2010), Underground (2010) e Potlatch (2012). Posteriormente publicou Bukkake (2012); Suburbia (2012); Cavalos Mortos permanecem no acostamento (2014); Jardim (2014); Cada caminho é um desvio (2014) e Incidente em Tunguska (2015). Esta última foi desenvolvida juntamente com sua pesquisa de mestrado em Artes Visuais na Universidade do Estado de Santa Catarina, sendo lançada como uma publicação impressa e também como dissertação em forma de exposição, na instalação Consideraçôes (2015). Em sua pesquisa, Pedro Franz explorou as interseções entre os quadrinhos e as artes visuais através da migração de imagens e dispositivos, de forma a pensar o que seriam os quadrinhos contemporâneos.

\section{Promessas de Amor a Desconhecidos Enquanto Espero o Fim do Mundo foi um} projeto independente, com apoio da Fundação Catarinense de Cultura, por meio de edital de estímulo à cultura, mas que só foi concretizado como publicação impressa por completo graças à relação entre leitores e autor. Por meio de um blog ${ }^{3}$, Pedro Franz expôs seu processo criativo, mantendo um contato direto com seus leitores e possibilitando um espaço de debate sobre a obra, que, apesar de ter uma ideia definida, construiu-se durante o processo de criação, tendo seus leitores como coautores, a partir das interaçóes via blog.

\footnotetext{
${ }^{2}$ BROERING, Pedro Franz. Promessas de amor a desconhecidos enquanto espero fim do mundo. Independente, 2011. Disponível em: https://issuu.com/pedrofranz/docs - acesso em 04.08.2017.

${ }^{3}$ Blog do projeto. Disponível em: https://sobreofim.wordpress.com/ - acesso em 04.08.2017.
} 


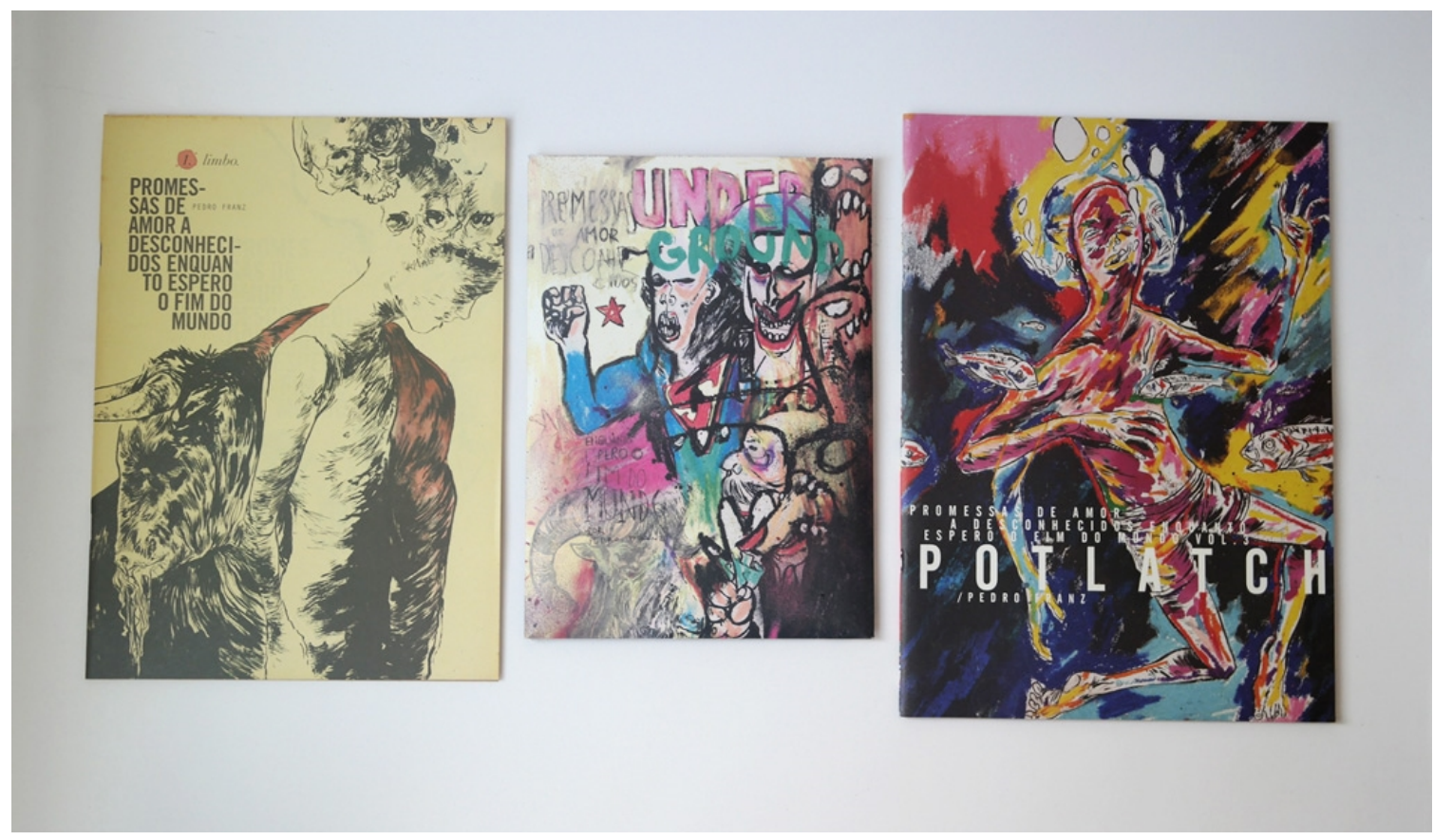

Figura 01: Fotografia da versão impressa da série. Disponível em: http://www.pedrofranz.com.br/promessas. Acesso em 08 de agosto 2017.

Desde o princípio, Pedro Franz planejava ter o trabalho como uma publicação impressa, conforme expôs em entrevista ${ }^{4}$ ao site da Vice, ciente que não se tratava de um quadrinho feito somente para internet, uma webcomic, mas um híbrido entre impresso e digital. Cada capítulo, após finalizado, foi disponibilizado online, mediante licença Creative Commons ${ }^{5}$, possibilitando assim sua distribuição gratuita. Mesmo a versão impressa posteriormente pode ser copiada e distribuída.

Durante o processo de criação foi pedido aos leitores do blog que enviassem fotos " $3 \times 4$ " para o projeto, como uma participação em troca da obra que era oferecida gratuitamente. Essa troca resultou na inserção das fotografias dos leitores em cada abertura de capítulo da trilogia. Retratos que, com intervençôes gráficas feitas pelo autor, como máscaras de caveira usadas pelo grupo Jolly Roger ou tarjas pretas velando os olhos, colocaram esses leitores como participantes da narrativa, refletindo sua importância na realização do projeto. A interação com os leitores foi crucial para

\footnotetext{
4 Entrevista realizada com Pedro Franz sobre o processo de construção da obra. Disponível em: https://www.vice.com/pt_br/article/ezgxwe/construindo-promessas - acesso em 04.08.2017.

${ }^{5}$ Licença criada por uma organização não governamental sem fins lucrativos com intuito de oferecer licenças que permitem a cópia, modificação e distribuição com menos restriçóes que o direito autoral oferece.
} 
finalização do terceiro volume da série, pois sua impressão foi financiada por um leiláo das páginas originais de Potlatch, realizado no blog.

Toda essa experimentação de mídias e suportes era um reflexo do que também foi explorado progressivamente na narrativa da HQ. O primeiro volume, Limbo, é iniciado em uma estrutura tradicional de história em quadrinho. Nele são apresentados personagens em diferentes narrativas divididas em capítulos com títulos descritivos que expõem os acontecimentos que virão, como o terceiro capítulo: "Após mostrar cenas de nudez, de sexo e de uso de drogas por crianças, utiliza-se uma conversa de bar para comentar a relação entre território e sociedade”. O título que é altamente explicativo vai contra a tradição de se criar expectativa ao longo da narrativa, comum na literatura, cinema e quadrinhos. A história acontece em uma Florianópolis de 2018, permeada por elementos fantásticos que, apesar disso, não se sobrepóem aos acontecimentos da ficção que são mais próximos da realidade e da sociedade atual.

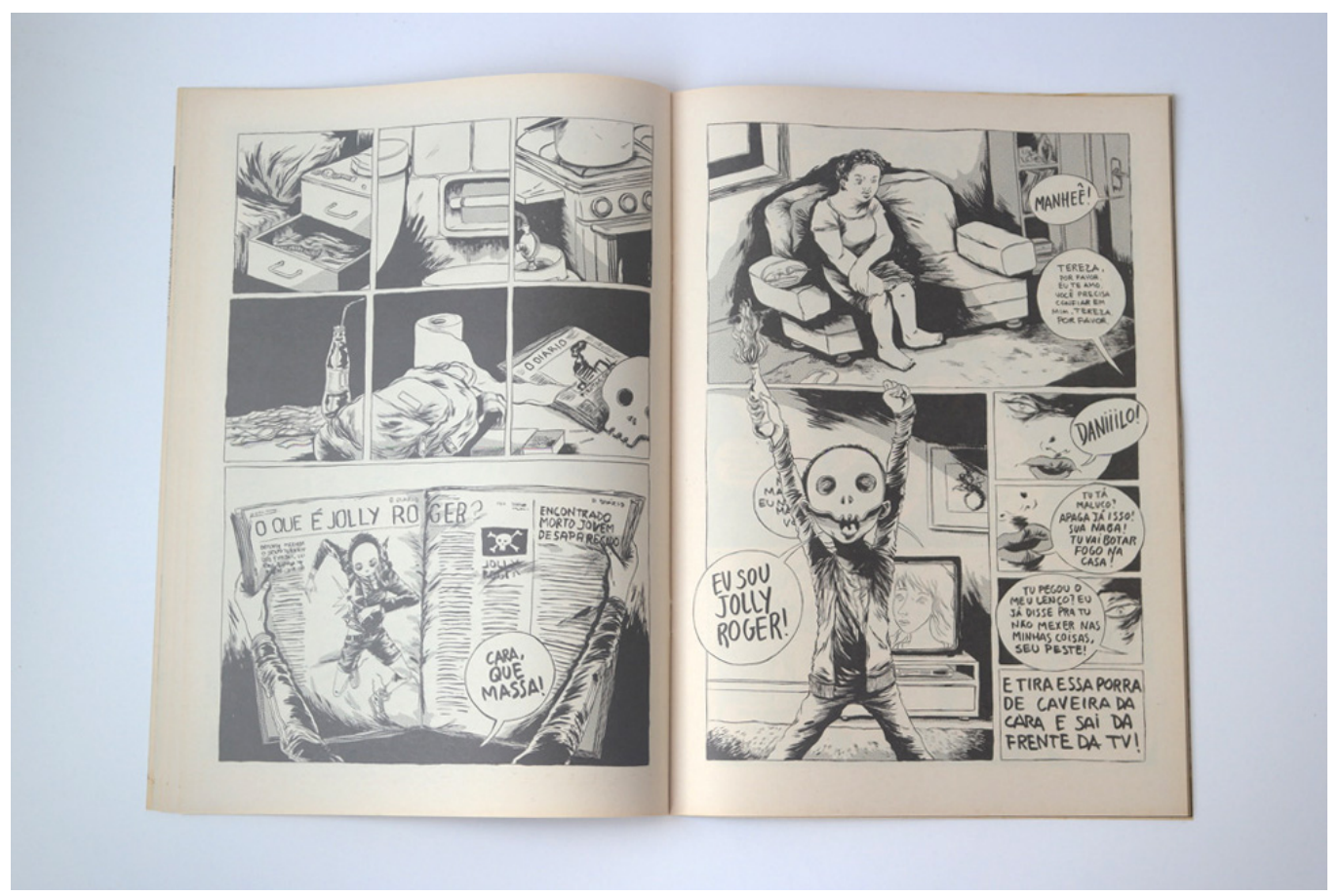

Figura 02: Versão impressa de Limbo. Disponível em: http://www.pedrofranz.com.br/promessas. Acesso em 08 de agosto 2017. 
No primeiro capítulo, "No qual Jolly Roger foge de seu esconderijo", é apresentada a narrativa central da $\mathrm{HQ}$, em que um grupo de jovens intitulado Jolly Roger é acusado de terrorismo por ter detonado uma bomba em um prédio do governo, deixando vítimas e feridos. Máscaras de caveira são utilizadas como símbolo de revoluçâo sem rosto ao longo de toda a história do quadrinho. Na Figura 02 o personagem Danilo exclama:" Eu sou Jolly Roger!”.

A proposta da revolução sem rosto remete ao pseudónimo literário $\mathrm{Wu} M \mathrm{Ming}$, que significa anônimo em mandarim, do projeto Luther Blissett. Como aponta Salvati (2010), o projeto consiste em uma proposta de ativismo anti-copyright em crítica ao Estado e ao modo de produçáo capitalista pelo qual diversos artistas e ativistas se intitularam Luther Blissett em suas açóes, a ideia teve início na Itália com artistas e ativistas na década de 1990 e espalhou-se pelo mundo via internet. Outra referência que o quadrinho traz é a máscara de Guy Fawkes, com origem em um personagem do quadrinho V for Vendetta (1982 - 1983) de Allan Moore, que se tornou um símbolo de revolução em manifestaçóes contemporâneas e, gradualmente, foi absorvida pela cultura pop, sendo replicada em filmes, séries de televisão, memes na internet e se tornando um produto de fácil acesso.

Também esteticamente, o primeiro volume Limbo remete a um formato tradicional de HQs que possuem elementos como vinhetas (delimitação dos quadros), sarjetas (espaço vazio entre os quadros), balôes de fala e toda a relação de solidariedade icônica que propóe Groensteen (2007) ao pensar a página de quadrinhos como um jogo de forças, um sistema espaço-tópico, onde os diferentes elementos gráficos ou textuais se articulam e possibilitam uma narrativa híbrida. Nos desenhos de Limbo, a anatomia do personagens e perspectivas de quadros criados por Franz aproximam-se dos quadrinhos do japonês Taiyō Matsumoto, como no mangá Preto e Branco (2001) que também apresenta corpos magros de jovens que "sobrevoam" a cidade. Já seu traço e a atmosfera da narrativa possuem uma densidade de preto que lembram, em alguns momentos, o estilo de Alberto Breccia, como no último capítulo "E Jolly Roger convida todos a 
tomarem as ruas" em que a estrutura dos quadrinhos torna-se mais abstrata e densa, assim como nas obras de Breccia.

Uma HQ não precisa ter, necessariamente, balóes de fala, personagens ou textos presentes em cada página para ser considerada um quadrinho, existem mais possibilidades dentro dessa linguagem. Este é o caso de Música para Antropomorfos (2006), de Fabio Zimbres e Mechanics, um marco nas HQs nacionais que uniu música e quadrinhos em um mesmo projeto colaborativo. Nela, a história foi construída intercalando uma estrutura tradicional de quadrinhos juntamente com uma narrativa mais abstrata, assim como obra de Pedro Franz. Esse tipo de quadrinhos, considerados abstratos, exploram os limites da linguagem, removendo elementos e intensificando o grau de abstração; eles exigem do leitor o papel de interpretar e criar sentido ou uma sensação para a HQ. Os quadrinhos abstratos, atualmente, já são reconhecidos e podem ser encontrados em publicaçóes como a antologia Abstract Comics (2009), editada por Andrei Molotiu e publicada pela editora Fantagraphics.

No último capitulo de Limbo é apresentada uma linha do tempo, entre páginas marcadas pelos anos 1894; 1979; 2005; 2009 e 2018. Tal linha do tempo aproxima-se da estrutura de um infográfico, em que o autor cria uma reflexão de passado e futuro sobre os conflitos sociais em Florianópolis, pautada por momentos marcantes da opressão e violência na cidade. O infográfico é dividido da seguinte forma: 1894 representado pelo ditador e ex-presidente Floriano Peixoto, conhecido como marechal de ferro, dá nome à cidade de Florianópolis; 1979 com a Novembrada, confronto entre população e presidente general João Baptista Figueiredo; 2005 e a Revolta da Catraca contra o aumento das passagens de ônibus na cidade; 2009 com a cena de um apresentador enaltecendo o período de ditadura militar, como aponta o autor em entrevista a Vice e, por fim, 2018 com o pronunciamento em uma transmissão pirata de um membro do grupo Jolly Roger. No pronunciamento, o grupo afirma que inventou o boato de bomba implantada em prédio do governo, mas que a realização do atentado foi concretizada por ações fora do grupo. Situação que pode remeter a fatos do período da ditadura no Brasil, como o atentado do Riocentro (durante as comemoraçóes do Dia do 
Trabalhador, em 1981), uma tentativa da extrema direita de forjar um ataque a bomba com fins de interromper o processo de abertura política. Ao fim, o grupo aceita ser julgado por algo que não fez e exige que o governo seja julgado pelos crimes de comete. Convida a populaçáo a tomar as ruas como processo de resistência pacífica e atenta-os para a manipulação de informação de mídias como a televisão, que podem apenas mostrar os conflitos e não suas causas. $\mathrm{O}$ autor cria, com esse esquema, uma forte crítica política por meio de levantamento histórico e leva a narrativa para a tensão entre realidade e ficção.

Com o grau de abstração maior da estrutura do último capítulo e o jogo entre realidade e ficção criado em Limbo, Pedro Franz proporciona uma transição entre a tradição e as experimentaçóes que são intensificadas de maneiras diferentes nos volumes seguintes da série, sempre mantendo a sua postura crítica e política. Em entrevista, ele aponta algumas intençóes sobre a obra.

$[\mathrm{N}]$ o Promessas havia uma vontade de evidenciar isso, de contar as três partes da história de forma diferente, até porque eram situaçóes muito diferentes. Esses três volumes, Limbo, Underground e Potlatch, a escolha desses nomes se deu como uma analogia entre Purgatório, Inferno e Céu. $\mathrm{O}$ primeiro, mesmo sendo a primeira parte, era quase como uma transiçáo, uma passagem para algo, muito mais convencional que os outros dois e isso se refletia no formato impresso, na escolha de um papel jornal e de ser um objeto mole, meio descartável, mais próximo às revistas antigas de banca. O segundo, Underground, era o extremo da situação (BROERING, 2015).

Pedro Franz, em Underground, aproxima o quadrinho a um campo das artes visuais, o livro de artista. Esse campo não possui uma definição ou limitação simples, como aponta Paulo Silveira em A página violada: Da ternura à injúria na construção do Livro de Artista (2001), pois engloba uma grande variedade de experimentaçôes no que se entende livro, como objeto e obra. Um dos precursores nessa proposta é o mexicano Ulisses Carrión, que em seu manifesto $A$ nova arte de fazer livros (2011) expóe um pensamento mais radical sobre o objeto livro, propondo a elaboração da estrutura do livro como elemento central de criação que possibilita transgredir página, texto, forma, ordem, leitura, os espaços que cada livro de artista poder ter, seu território e estrutura própria. 


\section{LITERARTES, N. 8, 2018 - ARTIGO - OLIVEIRA}

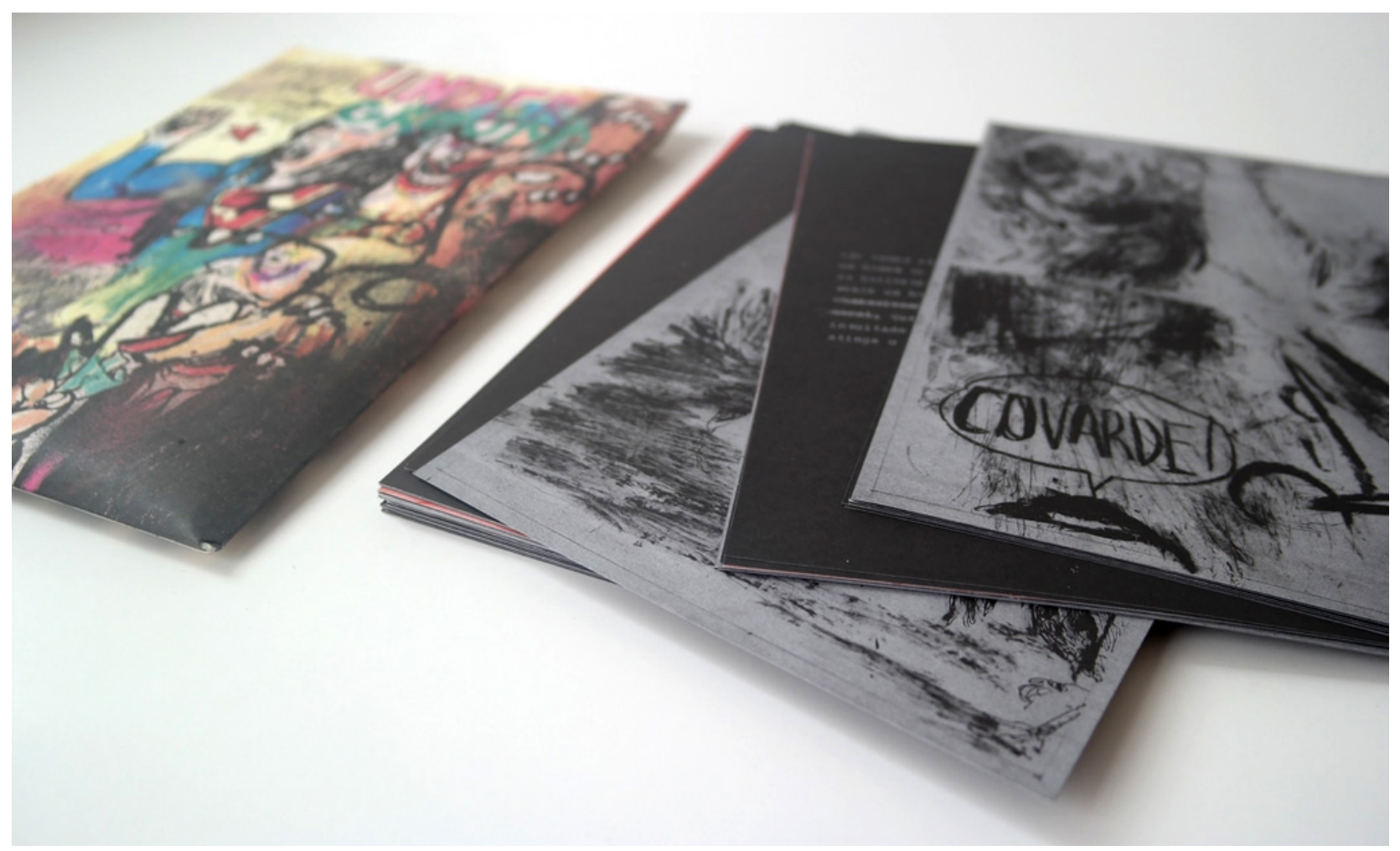

Figura 03: Folhas da versão impressa de Underground. Disponível em: http://www.pedrofranz.com.br/promessas. Acesso em 08 de agosto 2017.

Em Underground, o formato tradicional de livro é posto de lado em troca de uma estrutura de folhas soltas, sem uma ordem estabelecida, que condizem com o conceito de multidão e manifestações nas ruas onde a relação de caos e ordem permanece em constante tensão. Sem uma ordem estabelecida, cabe ao leitor percorrer as páginas, encontrar novos textos e ter sensação de que "o caos é apenas aparente", como o autor provoca em uma das páginas com texto datilografado e composto por intervençôes gráficas. A estrutura física de Underground funciona como elemento narrativo que determina a relação entre leitor e obra. Outra caraterística do segundo volume é o uso de apropriações, prática já estabelecida por artistas que utilizaram materiais do cotidiano como Picasso (1881-1973) em suas colagens cubistas, ou Duchamp (1887-1968) em seus ready mades. Na literatura nacional, temos como exemplo o escritor Valêncio Xavier (1933-2008), que utiliza fragmentos de jornais para criar seus romances que assim como na série de Pedro Franz, misturam elementos da realidade e criação ficcional, é o caso de $O$ mez da grippe e outros livros (1998) e na antologia Remembranças da menina de rua morta e nua (2006), apresentam histórias que são formadas 
por fragmentos de jornal e notícias do período em que foram criados. Nas HQs, um exemplo dessa prática é apresentado pelo próprio Pedro Franz (2015) em sua dissertação de mestrado: o grego Ilan Manouach, que em Katz (2012) apropria-se totalmente do quadrinho biográfico Maus, de Art Spiegelman, substituindo as cabeças dos personagens antropomorfizados que representavam povos e etnias diferentes em campos de concentração nazistas. Em Maus (1991), alemães são representados como gatos, poloneses não judeus como porcos, norte-americanos como cães e judeus como ratos. Já na versão Katz, todos passam a ser gatos e a história é publicada integralmente de forma anônima pelo grego.

Em Underground ocorrem diferentes apropriações: textos, citaçôes, frases e até uma página de um livro transformam-se em elementos da HQ, como é o caso do texto datilografado por Ana Cristina Cesar, extraído do livro Antigos e soltos: poemas e prosas da pasta rosa publicado em 2008, no qual a autora faz reflexóes sobre um enredo: "O enredo deste conto é um esquema simples e linear como um verdadeiro enredo. A diferença está em qual tal esquema se trai apenas no chicote do seu feitor: Dói menos um resto de enredo, os pensamentos do enredo, ou enredo apenas se pensado" (CESAR, 2013, p.386). O trecho é apropriado e reproduzido integralmente, criando, assim, uma reflexão sobre o que seria um enredo para Underground.

Outra apropriação é o texto Um Jogo Absorvente: Notas sobre a Briga de Galo Balinesa de Clifford Geertz, publicado no livro a Interpretação de Culturas (2015) lançado na década de setenta, que é reproduzido integralmente, de forma fragmentada, entre lâminas dos capítulos. Nele, Geertz relata suas experiências em Bali, destacando uma tradição da cultura local que são as brigas de galo. Esse evento, que é utilizado como reflexão sobre as relaçóes sociais humanas por Geertz, transforma-se em um paralelo direto com as manifestaçóes, os conflitos e a violência humana na HQ. Como no exercício presente, no capítulo "Quando a criança torna-se parte da multidão", que propóe imaginar aquilo que você mais ama sendo destruído na sua frente, no lado das lâminas que possuem desenhos é construída a sequência de imagens de um rosto sendo desfigurado, remetendo, assim, à violência do âmbito de quem sofre indiretamente, como um observador (ou o leitor) imobilizado, que apenas observa. 

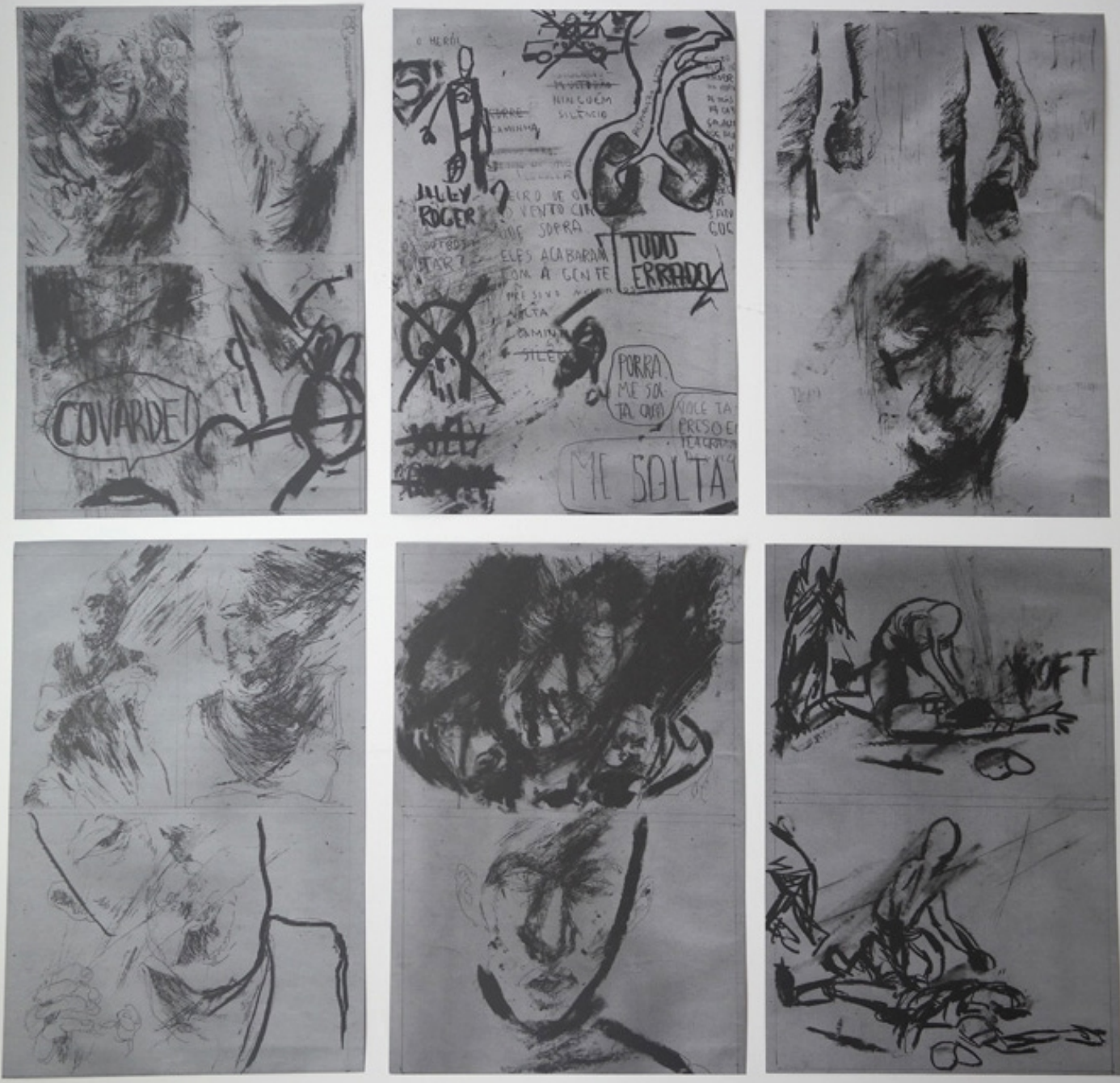

Figura 04: Lâminas da versão impressa de Underground. Disponível em: http://www.pedrofranz.com.br/promessas. Acesso em 08 de agosto 2017.

Os personagens já não são identificáveis como no primeiro volume, aqui eles são figuras, diálogos, fragmentos, desenhos inacabados, traços violentos, apropriaçóes, vozes, sensaçóes que se mesclam entre as lâminas. $\mathrm{O}$ autor apropria-se de modelos, como a figura do policial e do manifestante, e os agencia no território da narrativa nomeado com o mesmo nome Wagner Aguiar. Expondo características possíveis de cada agente, semelhantes em alguns pontos, tensionam a reflexão do que pode ser considerado um manifestante ou policial que, como personagens, também são construídos pela sociedade nesse conflito. $\mathrm{O}$ 
ritmo de Underground é pautado pelas páginas negras com texto e, no seu verso, desenhos densos e bruscos, que guardadas as devidas proporçóes, lembram a violência em obras do pintor Francisco de Goya e a expressividade do traço de Jean-Michel Basquiat, condizem com a narrativa e a ideia de manifestação, criando a sensação de caos e violência a que ela se propóe. Esse estilo de desenho mais sujo, com traços rápidos e fortes, que se mesclam com textos e balóes de fala em uma estrutura que remete a uma página de quadrinhos em rascunho, desfigurada ou mesmo abstrata, passa a ser uma característica marcante do autor, que reverbera em suas produçôes posteriores. $O$ traço e elementos gráficos utilizados representam mais do que uma marca de estilo, eles são cruciais na narrativa, como aponta Pedro Franz.

Vejo essas mutaçóes no Promessas como se fossem, talvez, as diferentes vozes narrativas em um romance. Como se o desenho fosse usado não apenas para representar algo, mas para produzir algo. E essas transformações no desenho são lidas. Se desenho algo (por exemplo, um rosto) com um traço fino e preciso isso é lido de uma forma, por outro lado, se desenho o mesmo rosto, mas utilizo um traço de pincel, grosso, desequilibrado, isso talvez crie uma leitura completamente diferente. Se estamos falando de narrativas, me parece que o traço então não pode ser uma questão apenas autoral. Ele deve trabalhar em função do que se está querendo dizer (BROERING, 2014).

Potlatch, último volume da série, retoma a estrutura de livro com páginas fixas e uma sequencia linear de leitura e estética de desenho, que pode ser considerada a junção entre Limbo e Underground, mas agora em cores fortes. A narrativa retorna ao personagem principal Lucas, revelando que ele era o manifestante em conflito com o policial, presente no último capítulo de Underground, que agora leva o corpo do policial pela cidade em sua jornada. O desenho passa a ter cores em um aspecto quase surrealista. Feito com giz pastel, as formas, textos, cores, personagens e demais elementos gráficos misturam-se pelas páginas em um ritmo fluido, mesmo nas cenas de violência e conflito. As páginas fluem como o mergulho de Lucas no mar, em um novo ciclo, ciclo continuo com que a narrativa prossegue até o capitulo final "Onde o herói encontra alguém e a história termina". 


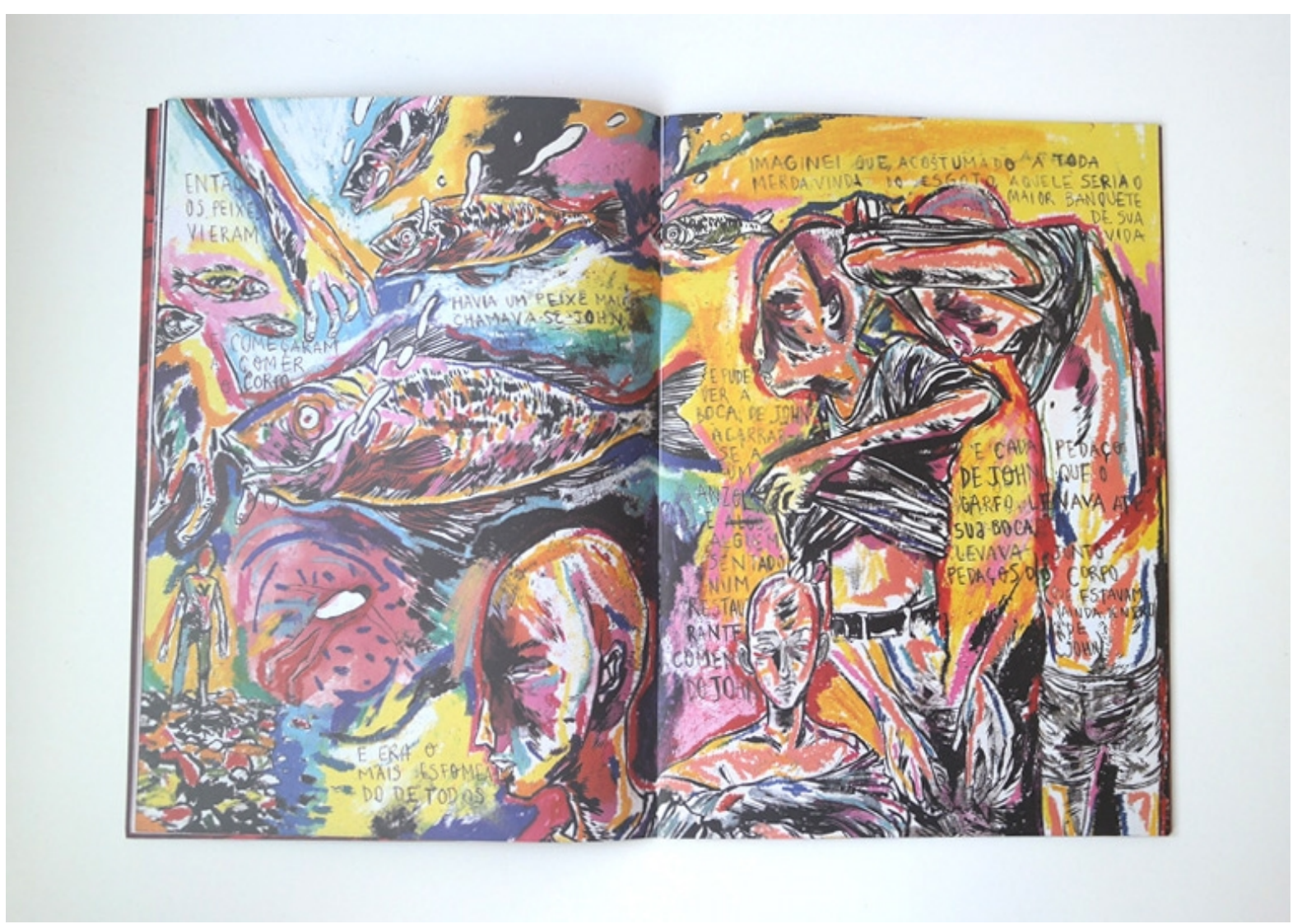

Figura 05: Páginas da versão impressa de Potlatch. Disponível em: http://www.pedrofranz.com.br/promessas. Acesso em 08 de agosto 2017.

No capítulo "Um vídeo se espalha. Uma fogueira é acesa”, as páginas são criadas em uma postura de metalinguagem, em que é desenhado um vídeo da manifestação, reproduzido ao longo das páginas, expondo o policial agredindo um jovem até a morte. A metalinguagem do vídeo, nas páginas, é interrompida para mostrar o corte da energia na ficção, que deixa a cidade em escuridão até o amanhecer chegar e as manifestações retornarem. O autor cria, aqui, novamente o diálogo entre forma e narrativa pautado nas imagens que variam de acordo com desenvolvimento dos acontecimentos da ficção. Essas, entre outras experimentaçóes, condizem com o que Pedro Franz propóe para Potlatch e também para a série como um todo.

Potlatch explorava a ideia desse desapego, de se desfazer de algo que você possui, de abrir mão de algo que lhe dá segurança. Talvez isso seja a própria ideia de experimentaçáo... buscar algo que você sabe que nunca vai encontrar, ou talvez que quando você encontra já não é mais o que você está procurando. A experimentação é então o caminho e que 
funciona para mim como uma espécie de jogo no qual você convida o leitor a jogar com as suas regras e me interessa a cada projeto rever/questionar essas regras para, se necessário, poder criar regras novas, conforme as possibilidades e necessidades narrativas do projeto (BROERING, 2014).

Ser contemporâneo, segundo Agamben (2009), não é estar em um estado de equilíbrio e conformidade com seu tempo, com o presente, pois assim não é possível manter a devida distância para observá-lo. É estar em um estado de desacordo com os usos e costumes de sua época, afastados do seu tempo, mas não de forma nostálgica. Conseguir visualizar no escuro do presente o que não é visto facilmente além das luzes que se direcionam a nós, que passam e seguem ao infinito. Perceber no presente os vestígios do arcaico, retirá-lo da linearidade para ter um olhar renovado como o tempo, um olhar sempre novo para o passado e para o presente, é o que Pedro Franz consegue alcançar em sua criação. Esse tipo de relaçáo com o presente, uma proposta contemporânea, é o local em que Promessas de amor a desconhecidos enquanto espero o fim do mundo se situa e convida seus leitores a uma exploração pelo universo da obra e seus outros pontos de referência. Não se conformando com as tradiçôes, a obra está em constante tensão com os territórios estabelecidos, Mantendo certa distância a cada experimentação, tensiona-se para novos territórios e, a cada volume, assim como a própria linguagem na $\mathrm{HQ}$, permanece em constante mutação. Não nega as luzes e acontecimentos da sociedade e tenta sempre ir além, levando o leitor da obra para um estado de criação e experimentação constante, que pode buscar, por meio dos fatos do passado, refletir o atual e observar a cidade do alto, no terraço, como o personagem Lucas ao final da HQ observando tudo o que está acontecendo na cidade. 


\section{REFERÊNCIAS}

AGAMBEN, Giorgio. O que é o contemporâneo? E outros ensaios. Tradução de Vinícius Nicastro Honesko. Chapecó: Argos, 2009.

BROERING, Pedro Franz. Incidente em Tunguska. Florianópolis. 2015. Dissertação (Mestrado em Artes Visuais) - Universidade do Estado de Santa Catarina - UDESC, Florianópolis, Santa Catarina, 2015.

BROERING, Pedro Franz. Promessas de amor a desconhecidos enquanto espero fim do mundo, 2010-2012. Disponível em: https://sobreofim.wordpress.com/ - Acesso em 8 ago. 2017.

BROERING, Pedro Franz. Os Minotauros, de Pedro Franz, maio de 2014. Disponível em: http://www.acalopsia.com/os-minotauros-de-pedro-franz/ - Acesso em 8 ago. 2017.

CADÔR, Amir Brito. O livro de artista e a enciclopédia visual. Belo Horizonte: Editora UFMG, 2016.

CARRIÓN, Ulises. A Nova Arte de Fazer Livros. Tradução de Amir Brito Cadôr. Belo Horizonte: C/Arte, 2011.

CESAR, Ana Cristina. Poética / Ana Cristina Cesar. São Paulo: Companhia das Letras, 2013.

DELEUZE, Gilles. Crítica e Clínica. Trad. de Peter Pál Pelbart. São Paulo: Ed. 34, 1997.

DELEUZE, Gilles e GUATTARI, Félix. Kafka: Por uma literatura menor. Trad. Cíntia Vieira da Silva. Belo Horizonte: Autêntica Editora, 2015.

DELEUZE, Gilles e GUATTARI, Félix. O que é filosofia? São Paulo: Ed.34, 1996.

GEERTZ, Clifford. A interpretação das culturas. Rio de Janeiro, 2015.

GROENSTEEN, Thierry. O sistema dos quadrinhos. Trad. Érico de Assis. Nova Iguaçu, RJ: Marsupial Editora, 2015.

MAZUR, Dan, DANNER, Alexander. Quadrinhos: história moderna de uma arte global. São Paulo: Martins Fontes, 2014.

SILVEIRA, Paulo. A página violada: Da ternura à injúria na construção do Livro de Artista. Porto Alegre: Editora UFRGS, 2001. 
SALVATTI, Fábio. O prank como opção performativa para a rede de ativismo politico contemporâneo. Tese (Doutorado em Artes Cênicas) - Universidade de São Paulo - USP, Sáo Paulo - SP, 2010.

XAVIER, Valêncio. O mez da grippe e outros livros. São Paulo: Companhia das Letras, 1998.

XAVIER, Valêncio. Remembranças da menina de rua morta e nua. São Paulo: Companhia das Letras, 2006.

ZIMBRES, Fábio e MECHANICS. Música para Antropomorfos. Goiânia: Livros Voodoo, 2006. 